\title{
Estimating the grid payments necessary to compensate additional costs to prospective electric vehicle owners who provide vehicle-to-grid ancillary services
}

\author{
Justin D K Bishop ${ }^{\mathrm{a}, \mathrm{b}, *}$, Colin J Axon ${ }^{\mathrm{c}}$, David Bonilla ${ }^{\mathrm{d}}$, David Banister ${ }^{\mathrm{e}}$ \\ ${ }^{a}$ Energy Efficient Cities Initiative, University of Cambridge Department of Engineering, Trumpington Street, Cambridge, \\ United Kingdom \\ ${ }^{b}$ Centre for Sustainable Road Freight Transport, University of Cambridge Department of Engineering, Trumpington Street, \\ Cambridge CB2 1PZ, United Kingdom \\ ${ }^{c}$ Institute of Energy Futures, Brunel University, Uxbridge, London UB8 3PH, United Kingdom \\ ${ }^{d}$ Institute of Economics, National University of Mexico, Mexico City, Mexico \\ ${ }^{e}$ Transport Studies Unit, School of Geography and the Environment, University of Oxford, South Parks Road, Oxford OX1 \\ $3 Q Y$, United Kingdom
}

\begin{abstract}
The provision of ancillary services in the smart grid by electric vehicles is attractive to grid operators. Vehicles must be aggregated to meet the minimum power requirements of providing ancillary services to the grid. Likely aggregator revenues are insufficient to cover the additional battery degradation costs which would be borne by an existing electric vehicle owner. Moreover, aggregator revenues are insufficient to make electric vehicles competitive with conventional vehicles and encourage uptake by prospective consumers. Net annual costs and hourly compensation payments to electric vehicle owners were most sensitive to battery cost. The fleet provided firm fast reserve from $1900 \mathrm{~h}$ for 0.42 hours, up to 2.7 hours in the best cases. At best, likely aggregator revenue was 20 times less than the compensation required, up to 27,500 times at worst. The electric vehicle fleet may not be large enough to meet the firm fast reserve power and duration requirements until 2020. However, it may not be until 2030 that enough vehicles have been sold to provide this service cost-effectively. Even then, many more electric vehicles will be needed to meet the power level and duration requirements, both more often and for longer to enable participation in an all-day, everyday ancillary services market.
\end{abstract}

Keywords: Electric vehicles, Lithium batteries, Vehicle-to-grid, Ancillary services, Battery degradation

\section{Introduction}

The two aims of this paper are to quantify: first, the battery degradation costs when electric vehicles (EV) are used both to satisfy travel demand and to provide V2G ancillary services; and second, the payments

\footnotetext{
*Corresponding Author: E: justin.bishop@cantab.net
}

$U R L:$ http://www.eng.cam.ac.uk (Justin D K Bishop) 
necessary from a power aggregator to compensate two group of consumers. The first group comprises existing $\mathrm{EV}$ owners who, by the end of the vehicle service life, will want to be left no worse off than if they had not participated in V2G. The second group represents prospective buyers who will compare the costs of EV ownership to that of a conventional vehicle. The motivation for including this second consumer group is that V2G is justified often on the basis that vehicles spend about $95 \%$ of their lifetimes stationary [1] and that the revenues from such participation can reduce the costs of ownership [2].

V2G may be used to store electricity generated off-peak which is returned to the grid during peak hours. Net social welfare benefits arise due to avoided construction of peaking generating plant [3]. A recent analysis of the V2G power capacity of a car park showed that 'peak-shaving' and regulation services returned the largest economic value, while spinning reserve could not be delivered profitably [4]. V2G can smooth the variations in output from generating plant using renewable energy sources. For example, EV providing V2G through high power connections reduced excess generation (and associated carbon dioxide emissions) from non-wind facilities and increased the efficiency of the power system [5]. Vehicle-to-building (V2B) is a local variation of $\mathrm{V} 2 \mathrm{G}$ which exploits the relationship between commuter and employer. Here, vehicles discharge to the building directly to shave the short peaks in demand which reduces costs to the facility [6]. V2B has a role in the residential context where it can reduce energy costs to the home, provide back-up power and maintain power quality [7].

V2G may be most cost-effective for owners of plug-in vehicles which participate in the short-duration, high-value power market of ancillary services. Specifically, vehicle owners receive two payments: one for the contracted capacity; and the other for the energy delivered. These capacity payments are the basis for V2G competitiveness because they augment the relatively low energy payments, which alone would render V2G unprofitable. The attractiveness of this scheme is dependent on the power level of the connections, vehicle battery capacity and the value of ancillary services [8]. The vehicle owner can benefit from a greater return when both ancillary services and peak power demands are met with V2G, than when each service is provided individually 9 .

The UK National Grid uses ancillary - reserve services and frequency response measures - services to balance demand with supply and to maintain the quality of electricity service, respectively. Examples of reserve services include fast reserve and short term operating reserve (STOR). STOR is the extra power necessary, either when actual demand exceeds that forecast, or to account for unavailability of generating plant. Frequency response mechanisms, such as firm frequency response and frequency control by demand management, are used to counter the real-time changes in system frequency when demand and supply are not matched. Frequency falls when demand exceeds supply and can be remedied by either increasing supply or reducing demand. Firm frequency response is a supply-side measure where a minimum $10 \mathrm{MW}$ is injected to the system to counter a fall in frequency. Frequency control by demand management involves interrupting 
services to customers for no more than 30 minutes 1

Of the ancillary services, firm fast reserve and firm frequency response may be met best by V2G. The 'firm' relates to the contract which providers enter into with National Grid to provide services on a consistent basis. Both services are attractive to V2G participants because of the two - energy and capacity - payments. Moreover, the time between a dispatch instruction and the duration that power must be fed into the system are short: specifically, firm fast reserve must be provided for a minimum of 15 minutes and start within two minutes of receiving a dispatch instruction [10; and secondary frequency response must be provided within 30 seconds of an event and sustained for 30 minutes [1].

Overwhelmingly, contributions to the V2G discussion quantify the benefits of such services to the power grid or system operator. The premise of current V2G models is that a vehicle, or group of vehicles, competes in a market to provide ancillary services. Common assumptions of these models include that vehicle batteries are charged fully both at the start of the day and at the time of grid disconnection [12] and charged and discharged at fixed rates [13. Additional assumptions are that vehicles connect: opportunistically [14], based on widespread charging infrastructure; during the day-time only, such as in the V2B scenario [6]; or during the night-time only [12], such as in the 'valley-filling' approach.

Providing V2G services may accelerate the degradation of EV batteries leading to the need for more frequent replacement [15], with associated costs borne by vehicle owners. Consequently, this work adopts their perspective and considers firm fast reserve (non-balancing mechanism) only as it can provide also some short term frequency control. The work in this paper is set in the UK context where the minimum requirements to provide firm fast reserve ancillary services to the National Grid are a: ramp rate of $25 \mathrm{MW}$ $\min ^{-1}$; a total power of $50 \mathrm{MW}$; a duration of service of 15 minutes; and the service must be in place within two minutes of receiving a request from National Grid [10. Satisfying these power and energy criteria requires the participation of multiple EV through a power aggregator. Appropriate charging infrastructure, metering, and communications system must exist to support the V2G interaction, the costs of which may not be borne by the vehicle owner alone.

In general, the existing V2G research makes assumptions on one or more of vehicle efficiency, consumer behaviour and battery degradation. Where powertrain modelling is not present, studies are based on either a constant vehicle energy use per distance travelled [16] or battery state of charge dropping linearly with distance travelled [13]. Driver behaviour influences the probability of vehicles being connected to the grid. However, works which do not incorporate real-world travel data make assumptions on at what time and for how long vehicles may be connected. For example, [13] assumed normal distributions for vehicle arrival and departure centred around peak driving hours of $0800 \mathrm{~h}$ and $1800 \mathrm{~h}$. In contrast, this work uses models

${ }^{1}$ The range of reserve services are described online at http://www2.nationalgrid.com/uk/services/balancing-services/ reserve-services/ 
of both EV powertrains and battery degradation, paired with national travel survey data to determine the costs to the vehicle owner which need to be compensated by V2G ancillary service provision.

The method presented is flexible and applicable in different national circumstances. There are three bases which support this statement. First, the vehicle market is global. For example, the Nissan Motor Company reported the Nissan LEAF as the best-selling EV, accounting for $45 \%$ of the market, having sold 110,000 units globally between December 2010 and June 2014 [17. Second, similar driving behaviour has been observed in different national travel surveys. In the US, the peaks in trip start times occurred at 0700h and 1700h [18. Third, ancillary services are a power system requirement which is independent of whether the system operates through markets or remains part a vertically-integrated structure. Indeed, the number of studies investigating V2G ancillary services illustrates a demand for such services across regions and countries.

\section{Method}

The cost calculation method has three principal elements which addresses assumptions in others' models of energy demand by EV on the grid. The first is an empirically-derived battery degradation model. The second is a validated powertrain model simulated over the New European Driving Cycle (NEDC) to give per second current flows through battery pack while driving. The third is a comparison with the costs associated with the equivalent conventional vehicle to reflect the choices faced by prospective EV owners. Together these form a system which both quantifies and internalises the cost burden on the vehicle (and battery) owner when providing V2G services.

The UK National Travel Survey (UKNTS) [19] provided realistic patterns of vehicle availability for the grid. The UKNTS consists of 1.1 million trips (years 2008-2013). The median velocity, distance travelled and duration are $29 \mathrm{~km} \mathrm{~h}^{-1}, 11 \mathrm{~km}$ and $0.38 \mathrm{~h}$, respectively. The highest frequency of trip start times in the morning and afternoon occurred at 08:00 $\mathrm{h}$ and 15:00 h, respectively; the mean trip interval was seven hours. The probability distribution for vehicle activity in any hour of the day is given in [15].

The UKNTS trip distribution, coupled to opportunistic charging, represents the best case for vehicles to participate in $\mathrm{V} 2 \mathrm{G}$ services for two main reasons. The first is that if a vehicle is connected to the grid whenever it is stationary, the battery pack is only depleted by the energy used to deliver the immediate preceding journey. Therefore, the pack will have a high state of charge for meeting grid demands when connected. The second reason is that a vehicle that is always connected when stationary maximises its availability to the grid. Opportunistic charging removes the need to assume specific driver behaviour. However, the driver may choose to charge when it is most disadvantageous to the grid which could have negative impacts at large scale EV deployment. 
where: $n_{\text {level }}=$ the number of vehicles required to ensure a $50 \mathrm{MW}$ discharge power is achieved; modelled in ADVISOR version 2003-00-r0116 20] on Matlab R2015a and the costs of ownership compared to the published figures of the Nissan Pulsar as the closest equivalent conventional vehicle from the same manufacturer. The base Pulsar was used with a retail price of $£ 15,995$ and fuel economy of $56.5 \mathrm{mpg}^{3}$ Technical specifications for the Nissan LEAF is given in Table ??.

The Nissan LEAF battery was modelled using a 18650-style Li-ion and designed to deliver $440 \mathrm{~W} \mathrm{~kg}^{-1}$, $180 \mathrm{Wh} \mathrm{kg}^{-1}$ and a maximum 3,000 cycles at 75\% depth of discharge (DOD). The degradation model is presented in [21] and validated across a range of C-rates 4 and temperatures. The batteries used in this work may not be the exact type used in the LEAF. However, the battery degradation model used is valid for Li-ion battery chemistries with similar ageing mechanisms to the 18650-style cell. Therefore, the model used is appropriate for the batteries chosen in this paper and is expected to be applicable to real-world EV batteries. The C-rate was fixed at each time step (of five minutes) of both the vehicle driving cycle and V2G participation, but could be different between time steps (quasi-static). Constant current charging and a constant temperature of $298 \mathrm{~K}$ were assumed. The end of the battery life was marked by a $20 \%$ capacity fade.

\subsection{Electricity grid requirements}

Firm fast reserve services require an analysis of the availability of power and energy from the vehicles at the fleet level. The distribution of trip start and end times reduced the number of hours which the fleet was available to provide the power level of $50 \mathrm{MW}$ for the 15-minute duration (three 5-minute time steps). The minimum number of vehicles required to meet the power level was:

$$
\text { Fleet } P=P_{\text {dischargeI }} \cdot V_{\text {grid }} \cdot n
$$

where: Fleet $P$ is the fleet discharge power $(\mathrm{MW})$ to the grid; $P_{\text {dischargeI }}$ is the probability distribution of discharge current for each time step of the day based on vehicle trip behaviour and charging regime; $n=$ the first assumption of vehicle number at 16,026 which is the quotient of the $50 \mathrm{MW}$ power level target and the $3.1 \mathrm{~kW}$ maximum power that the $\mathrm{EV}$ can provide on a $13 \mathrm{~A}, 240 \mathrm{~V}$ circuit; $V_{\text {grid }}=$ grid voltage of $240 \mathrm{~V}$.

$$
n_{\text {level }}=\frac{(50-\max (\text { Fleet } P))}{P_{\text {dischargeI }} \cdot V_{\text {grid }}+1}
$$

The Nissan LEAF ${ }^{2}$ is the best-selling EV in the UK, with 1,774 registered for the first time in 2013. It was

\footnotetext{
${ }^{2}$ Nissan LEAF specification: www.nissan.co.uk and www.carfolio.com/specifications/models/car/?car=220715

${ }^{3}$ See http://www.nissan.co.uk/GB/en/vehicle/city-cars/pulsar/prices-and-equipment/prices-and-specifications/ model-details.107420_105374_105902.html for Nissan Pulsar technical specifications.

'The current necessary to discharge the battery completely in one hour.
} 
For each time step that the power was greater than $50 \mathrm{MW}$, the preceding $\left(\mathrm{C}^{-}\right)$and following $\left(\mathrm{C}^{+}\right)$time steps were checked to verify a fleet power greater than $50 \mathrm{MW}$ had been achieved to meet the requirement of three consecutive time steps. If this condition was not satisfied, the fleet was increased by enough to close the larger of the two gaps: $50 \mathrm{MW}$ and the fleet power in $\mathrm{C}^{+}$; and $50 \mathrm{MW}$ and the fleet power in $\mathrm{C}^{-}$.

Currently, companies tender to provide fast reserve and include the compensation which they are willing to accept for the service. In 2013, median compensation for energy delivered was $£ 145 \mathrm{MWh}^{-1}$ and $£ 805 \mathrm{~h}^{-1}$ for committing the plant to be available5. The fleet aggregator is expected to receive the revenues of providing ancillary services and distribute the proceeds to the vehicle owners, after covering its costs. The aggregator may employ two strategies to encourage EV owners to participate in providing V2G services. First, EV owners may be allowed to participate on a pay-as-you-go basis, rather than being required to sign a contract. Second, the aggregator may remit an upfront cash payment to the EV owner in exchange for signing a contract [2].

\subsection{Costs of ownership and operation}

The costs of owning and operating (excluding maintenance) an EV were assessed with and without participation in V2G services. The retail prices for petrol and diesel in 2013 were $£ 1.37 \mathrm{l}^{-1}$ and $£ 1.41 \mathrm{l}^{-1}[?$ ], respectively. The attractiveness of owning an EV was represented by amortised annual payments which converted the purchase price and ongoing operating costs to a net present value. The interest rate was $1.79 \%$, representing the increase in UK gross domestic product over 2012-136

The compensation to each EV in the aggregator fleet were based on the two consumer types described earlier. Recall the first consumer type is the existing EV owner who wishes to recover any additional costs associated with providing $\mathrm{V} 2 \mathrm{G}$ services over the vehicle lifetime. The second consumer type is the prospective EV owner who wishes the V2G compensation payments to cover any costs, beyond those of owning a conventional vehicle, across two time horizons: the first was no financial penalty over the asset lifetime of 7.7 years 7 and the second was no financial penalty after year two, reflecting the desire of consumers to realise a payback on fuel efficiency expenditures within 18 months [? ] (Figure 1).

\footnotetext{
${ }^{5}$ Plant availability compensation comprised $£ 0$ window ${ }^{-1}$ for window initiation, $£ 450 \mathrm{~h}^{-1}$ for positioning plant and $£ 355 \mathrm{~h}^{-1}$ for committing plant availability. Prices are the median of accepted bids FFES1,2,3 and CRUA-1,4 for 2013. Monthly fast reserve market reports are available at http://www2.nationalgrid.com/UK/Industry-information/ Electricity-transmission-operational-data/Report-explorer/Services-Reports/

${ }^{\circ}$ Latest UK GDP deflator figures are available from HM Treasury at https://www.gov.uk/government/statistics/ gdp-deflators-at-market-prices-and-money-gdp-december-2014-autumn-statement

'See UK Department for 'Transport Table VEH0211, available online at https://www.gov.uk/government/ statistical-data-sets/veh02-licensed-cars
} 


\section{Results and discussion}

The ADVISOR model of the Nissan LEAF over the NEDC produced an energy use of $161 \mathrm{Wh} \mathrm{km}^{-1}$ which is $7.3 \%$ higher than the published figures of $150 \mathrm{Wh} \mathrm{km}^{-1}$. Daily battery degradation was $0.005 \%$ for the EV over two runs of the NEDC, representing the morning and evening trips, and corresponds to a battery lifetime of 12 years with no V2G.

The base case Nissan LEAF provided firm fast reserve by discharging its battery by up to $30 \%$ through an aggregator with the results presented in Table ??. Here, each vehicle: had an all-electric range (AER) of $199 \mathrm{~km}$; used a $24 \mathrm{kWh}$ battery costing $£ 400 \mathrm{kWh}^{-1}$ [? ]; connected opportunistically to the grid using a 13 A, Level 1 (L1) charger; and replaced the battery when a 20\% capacity fade was reached. The battery wear associated with providing firm fast reserve led to degradation costs of $£ 0.17 \mathrm{~km}^{-1}$ and a net annual cost of $£ 10,900$ per vehicl $\oint^{9}$ The daily battery degradation rate required replacement of the pack every 1.7 years.

Under opportunistic charging, the firm fast reserve requirements were met using 44,300 EV connected for $0.42 \mathrm{~h}$ beginning at $1900 \mathrm{~h}$. Therefore, the aggregator was likely to receive only $£ 335$ (from $£ 805 \mathrm{~h}^{-1}$ ) for positioning the fleet and making it available. However, the existing EV owner required hourly payments of $£ 37$ to leave each owner no worse off over the vehicle lifetime. This compensation was equivalent to $£ 1.6$ million for the 44,300 EV fleet. Likewise, a prospective EV owner would need hourly payments of £52 (£2.3 million to the fleet) to be no worse off economically than owning and operating a conventional vehicle over its lifetime. Hourly capacity payments of $£ 64$ per vehicle (£2.8 million for the fleet) were needed to reduce the net annual costs to that of a conventional vehicle by the end of the second year. Therefore, the likely aggregator revenues were 4,900-8,400 times lower than what was necessary for all the costs of EV providing firm fast reserve to be recovered.

Sensitivity analyses were performed on the factors affecting EV ownership and operating costs, namely: battery capacity and AER; charging regime; DOD for firm fast reserve; battery cost; charging level; and endof-life criterion for the battery. The AER desired by the vehicle owner determined the battery capacity for a particular vehicle size and its capital cost. The trip purpose and the availability of recharging infrastructure formed behavioural and technical limits, respectively, to the amount of time and energy that the fleet could provide a V2G service. The DOD of each vehicle battery influenced both its degradation costs and the number of vehicles needed to meet the power level and duration requirements of firm fast reserve. The battery cost was a factor in the vehicle purchase price and ongoing costs associated with battery replacement.

\footnotetext{
${ }^{8}$ See http://www.nissan.co.uk/dam/services/gb/brochure/Nissan_Leaf_technical_specs.pdf for performance and pric-

${ }^{9}$ Data in the results discussion is rounded to assist in reading and understanding the main arguments. Data to full accuracy is available in the tables.
} ing. 
Finally, the criteria to determine battery end of life impacted the frequency of battery replacement and associated annual costs.

\subsection{Battery capacity for AER}

The battery capacity varied from $50 \%$ to $150 \%$ of the base case, corresponding to an AER range of 89-238 km. Battery degradation increased as a quadratic with battery capacity $\left(\mathrm{R}^{2}>0.99\right)$ and net annual costs rose 2.8 times over that range, from $£ 5,000$ to $£ 14,000$ as illustrated in Figure $2 \mathrm{a}$ and $2 \mathrm{~b}$, respectively.

Battery capacities of $12 \mathrm{kWh}$ and $16 \mathrm{kWh}$, corresponding to AER of $89 \mathrm{~km}$ and $103 \mathrm{~km}$, respectively, would need to be replaced every 2-2.3 years. Larger capacity battery packs would need to be replaced more often at every 1.4-1.9 years. There were three vehicle fleet sizes to meet the firm fast reserve level of $15 \mathrm{MW}$ 54,300 vehicles for battery capacities of $12 \mathrm{kWh}, 16 \mathrm{kWh}$ and $18 \mathrm{kWh}$; 44,300 vehicles for battery capacities of $21 \mathrm{kWh}, 24 \mathrm{kWh}$ and $26 \mathrm{kWh}$; and 31,800 vehicles for higher battery capacities. Therefore, the vehicle fleet for achieving the $50 \mathrm{MW}$ level decreased as a quadratic with increasing battery capacity $\left(\mathrm{R}^{2}>0.90\right)$.

In half the cases (battery capacities of $16 \mathrm{kWh}, 18 \mathrm{kWh}, 24 \mathrm{kWh}$ and $26 \mathrm{kWh}$ ), no additional vehicles were required to provide meet the 15-minute duration requirement. In the other cases: 63,700 EV were required for battery capacities of $12 \mathrm{kWh} ; 18,700 \mathrm{EV}$ for battery capacity of $21 \mathrm{kWh}$; and 16,900 kWh for capacities of $30 \mathrm{kWh}$ and $32 \mathrm{kWh}$. These larger fleets were generally connected for longer, ranging from $1.6 \mathrm{~h}$ for fleets with $30 \mathrm{kWh}$ battery pack capacity up to 2.7 hours for fleets with $12 \mathrm{kWh}$ battery packs. All start times were $1900 \mathrm{~h}$ because vehicles charged opportunistically. Total fleet sizes for each AER are shown in Figure 2c.

Across all battery capacities, the smallest hourly payments were observed for the smallest battery capacity of $12 \mathrm{kWh}$, shown in Figure 2d. Here, the EV owner required $£ 1 \mathrm{~h}^{-1}$, equivalent to $£ 145,000$ to the whole fleet, to recover battery degradation costs associated with providing firm fast reserve. The aggregator might expect to receive $£ 2,100$ from the grid for making the fleet available for 2.7 hours. Therefore, the likely revenues to the aggregator was 65 times lower than the minimum payments to the EV owners. Prospective EV owners required hourly payments per vehicle of $£ 2$ and $£ 5$ if they were to be no worse off than owning a conventional vehicle over its lifetime or after two years, respectively. These hourly payments were equivalent to $£ 243,000$ and $£ 584,000$, respectively and were 110 times and 270 times lower than what the aggregator might receive, respectively. Full results are given in Table ??.

\subsection{Charging regime}

Sensitivity to V2G services was evaluated based on charging behaviour - opportunistic, at home only or at work only (Figure 3) - and the amount of energy the battery was permitted to discharge.

Opportunistic and home only charging required 44,300 EV each to meet the $50 \mathrm{MW}$ power level and the 15-minute duration requirements of firm fast reserve. In both cases, fleets connected at $1900 \mathrm{~h}$ for $0.42 \mathrm{~h}$. 
However, charging at work only needed 54,300 EV to provide $50 \mathrm{MW}$ for 15 minutes which occurred at 0930h for $0.25 \mathrm{~h}$. Battery degradation costs per km fell from $£ 0.17$ for opportunistic charging to $£ 0.13$ when charging at work only and $£ 0.12$ at home only. Similarly, annual costs fell from $£ 10,900$ for opportunistic charging to $£ 7,500$ when charging both at home only and at work only. Restricting charging to one of these two locations led to battery lifetimes of 2.3-2.4 years).

For home only charging, the aggregator would be required to make hourly per vehicle payments to the EV owner of $£ 20$ to cover the additional battery degradation costs associated with providing firm fast reserve. A prospective EV owner would need to receive $£ 30$ and $£ 61$ to make the EV no more expensive to own and operate compared to a conventional vehicle with eight years and two years, respectively. Opportunistic charging led to battery lifetimes of 1.7 years and required payments from the aggregator of £37 to the existing EV owner and $£ 52$ and $£ 64$ to the prospective EV owner for payback within two years and over the vehicle lifetime (4,900-8,400 times what might be received), respectively. Hourly payments for work only charging to existing EV owners would need to be $£ 33$ and to prospective EV owners of $£ 50$ and $£ 100$. These payments to the fleet exceeded the $£ 805$ per hour which the aggregator was likely to receive by 2,700-27,500 times across the three charging regimes. Full results are given in Table ??.

\subsection{Individual vehicle battery DOD for firm fast reserve}

As battery DOD increased for the EV, battery degradation costs increased linearly as shown in Figure 4a. However, battery replacement was annual across the DOD range. Therefore, net annual costs were fixed at $£ 10,900$ and illustrated in Figure 4b. Total vehicle fleet size increased linearly with increasing battery DOD $\left(\mathrm{R}^{2}>0.96\right)$. In every case, save $\mathrm{DOD}=40 \%$, no additional vehicles were required to meet the 15 -minute duration requirement, as shown in Figure 4c. Here, blue and yellow bars represent the number of vehicles required to the meet the power level and duration, respectively. The median connection time across the DOD range was $0.42 \mathrm{~h}(0.33-0.50 \mathrm{~h})$ beginning at $1900 \mathrm{~h}$. Hourly payments decreased as a quadratic with increasing DOD range $\left(\mathrm{R}^{2}>0.99\right)$ across the two consumer groups. Existing EV owners required a median hourly payment of $£ 37$ (£31-46). Prospective EV owners required median hourly payments £52 (£43-65) per vehicle (£1.2-3.5 million for the fleet) and £64 (£53-80) per vehicle (£1.5-4.3 million for the fleet) to be no worse off than owning a conventional vehicle over its lifetime or after the second year, respectively.

For $40 \%$ DOD, the firm fast reserve requirement of $50 \mathrm{MW}$ was met by 31,800 vehicles and 16,900 vehicles additional vehicles were required to satisfy the 15-minutes duration. This larger fleet was connected for 1.7 hours beginning at $1900 \mathrm{~h}$. Consequently, hourly capacity payments to the aggregator were the largest. The longest connection time coincided with the largest fleet and led to minimum hourly payments of £9 (£452,000 for the fleet) to existing EV owners. This is shown as the smallest stacked bar in Figure 4d. Prospective EV owners required $£ 13$ per vehicle ( $£ 633,000$ for the fleet) to recover costs over the vehicle lifetime and $£ 16$ per vehicle (£775,000 for the fleet) within two years, relative to owning a conventional vehicle. 
Across the DOD range, the aggregator could expect to receive $£ 270-1,300$ from the grid to compensate for being connected for 0.33-1.7 hours. Therefore, the gap between likely aggregator receipts and what would be required by the fleet was 340-16,000 times. Full results are given in Table ??.

\subsection{Battery costs}

The sensitivity of net annual costs and capacity payments to battery cost was considered for the range of $£ 200 \mathrm{kWh}^{-1}$ [? ], as the lower bound expected of future Li-ion battery prices to $£ 800 \mathrm{kWh}^{-1}$ [? ]. Recent analysis [? ] suggests current median battery prices are $£ 273 \mathrm{kWh}^{-1}\left(£ 167-447 \mathrm{kWh}^{-1}\right)$ using an exchange rate of GBP1 $=$ USD1.5.

The net annual costs of the EV with minimum battery pack cost providing ancillary services was $22 \%$ lower than the base case. Fleet size, connection start time and duration were unchanged from the base case. The hourly capacity payments over both horizons increased linearly with battery cost $\left(\mathrm{R}^{2}=1\right)$. The EV fleet with a $£ 200 \mathrm{kWh}^{-1}$ battery pack required an hourly capacity payment of $£ 24$ to the existing EV owner to recover additional battery degradation costs. The prospective EV owner required hourly payments of $£ 35$ and $£ 44$ to be no worse off than owning a conventional vehicle by the end its lifetime and by the second year, respectively. These payments were 3,100 times and 5,900 times, respectively, higher than what the aggregator might receive. Full results are given in Table ??

\subsection{Charging level}

Sensitivity to V2G services was evaluated based on the three charging levels available in the UK: level L1, single phase 12.5 A at $240 \mathrm{VAC}$; level L2, single phase $21 \mathrm{~A}$ at $240 \mathrm{VAC}$; and level L3, three phase $63 \mathrm{~A}$ per phase at $240 \mathrm{VAC}^{10}$. These charging levels were assessed under five charge/discharge combinations: both charge and discharge at L1, L2 and L3; charge at L1 and discharge at either L2 or L3 as a smart scheme which prioritises battery discharge for V2G services; and charge at L2 or L3 while discharging at L1 which prioritises battery recharging for the next trip and minimises $V 2 G$ the contribution to the grid.

Changing the charge/discharge rate had little impact on the daily energy throughput (119-123 Ah) because the battery was discharging by $30 \%$ only. Therefore, the battery degradation rate and associated costs were stable at $0.033-0.034 \% \mathrm{~km}^{-1}$ and $£ 0.17-0.19 \mathrm{~km}^{-1}$ across the five charge/discharge combinations and illustrated in Figure 5a. In all cases, battery replacement was every 1.7 years which required positive hourly payments from the aggregator if costs were not to exceed that of a conventional vehicle, both over two years and the vehicle lifetime.

The charging level affected the number of vehicles required in the fleet to meet the $50 \mathrm{MW}$ power and 15minute duration requirements. The number of vehicles necessary to meet the power requirements decreased

\footnotetext{
${ }^{10}$ See http://ukevse.org.uk/charge-points-chargers/ for a description of the three charging levels.
} 
as charge/discharge rates increase from L1/L1 (44,300 vehicles for $0.42 \mathrm{~h})$ to L2/L2 (32,300 vehicles for $0.25 \mathrm{~h}$ ). Payments of at least $£ 37$ were required by existing EV owners, increasing to at least $£ 52$ for prospective owners under both L1/L1 and L2/L2, equivalent to at least 4,900 times what might be paid by the aggregator.

For L3/L3 charge/discharge rates, a fleet of 25,700 vehicles was sufficient to meet the power requirement. An additional 30,200 was needed to meet the duration requirement, shown as a yellow bar in Figure 5c at charging level 3. The total fleet at L3 charge/discharge rates met the ancillary service demands for $2.3 \mathrm{~h}$. This long connection time led to the lowest hourly payments of $£ 7$ to existing EV owners and £9 for prospective owners. These low payments are illustrated by the smallest stacked bars in Figure 5d. The likely aggregator revenues were still exceeded by at least 280 times.

Fleet size and hourly payments from the aggregator were sensitive to the discharge rate under both smart charging schemes. The smart connection schemes favouring V2G services (L1/L2 and L1/L3) displayed the same fleet size and required hourly payments from the aggregator as under L2/L2 and L3/L3, respectively. Likewise, the smart connection scheme favouring battery charging (L2/L1 and L3/L1) yielded the same values as the L1/L1 case. Full results are given in Table ??.

\subsection{End-of-life criterion for batteries}

Traditionally, batteries reach the end of their life with a $20 \%$ capacity fade. However, a better assessment of whether a battery is still fit for purpose is to consider its ability to satisfy driving needs. In this case, over half of all trips in the US were achieved even with a $70 \%$ battery capacity fade [? ]. Therefore, the sensitivity of costs to end of life criterion, ranging from $20 \%$ to $70 \%$ in $10 \%$ intervals, was investigated.

Battery degradation fell linearly as the end of life criterion was relaxed from $20 \%$ to $70 \%$ capacity fade $\left(\mathrm{R}^{2}>0.99\right)$ from $£ 0.17 \mathrm{~km}^{-1}$ to $£ 0.14 \mathrm{~km}^{-1}$ as in Figure 6a. Likewise, net annual costs by $51 \%$ from $£ 10,900$ to $£ 5,500$ (Figure 6 b) as the battery pack replacement frequency decreased from 1.7 years to 7.2 years over the same capacity fade range. EV fleet size to meet the $50 \mathrm{MW}$ firm fast reserve power requirement increased linearly with a relaxation of end of life criterion $\left(\mathrm{R}^{2}>0.82\right)$. Fleet size was 44,300 for capacity fade up to $30 \%, 54,300$ for capacity fade of $40-60 \%$ and 68,500 for a $70 \%$ capacity fade. An additional 18,700 EV, 63,700 EV and 80,400 EV were required to meet the firm fast reserve 15-minute duration requirement for capacity fades of $30 \%, 60 \%$ and $70 \%$, respectively.

The smaller fleets (fewer than 100,000 vehicles) were connected for a median $0.42 \mathrm{~h}(0.33-0.58 \mathrm{~h})$. Required hourly payments to the two EV owner groups decreased as a quadratic $\left(\mathrm{R}^{2}=1\right)$ with increasing $(20 \%$, $40 \%$ and $50 \%$ ) capacity fade. The $18,700 \mathrm{EV}$ required to meet the firm fast reserve duration requirement coincided with the longest connection time of 0.58 hours for a $30 \%$ capacity fade. The consequence of a large number of vehicles connecting for a long time was less burden per vehicle, leading to lower compensation payments. Here, the existing EV owner needed £6 per hour to recover battery degradation costs, while 
prospective EV owners would need $£ 16$ and $£ 29$ to be left no worse off than owning a conventional vehicle by the end of its lifetime or within two years, respectively.

Connection time increased to 2.7 hours and 2.3 hours for capacity fades of $60 \%$ and $70 \%$, respectively. Total fleet sizes were now 118,000 EV and 149,000 EV, respectively. These much larger fleets connected for the longest times yielded the lowest hourly payments required across the scenarios investigated, illustrated using the smallest stacked bars in Figure 6d. Existing EV owners required less than £1 per hour to recover costs, while prospective EV owners would need up to $£ 7$ to be left no worse off than owning a conventional vehicle after two years. The gap between likely grid payments to the aggregator and the total disbursement to the fleets remained at least 20 times. Full results are given in Table ??.

\subsection{Comparisons across sensitivity analyses}

Figure $7 \mathrm{a}, \mathrm{b}$ and $\mathrm{c}$ illustrate the sensitivity of battery degradation costs, annual costs and hourly payments, respectively, to the six scenarios evaluated in this work. Battery degradation costs, net annual costs and hourly payments were each most sensitive (highest range of values) to the initial battery cost. After battery cost, both battery degradation costs and net annual costs were most sensitive to the battery capacity/AER. Hourly payments both to existing EV owners and prospective EV owners wishing to recover costs over the vehicle lifetime were most sensitive to charging level. Hourly payments to prospective EV owners to leave them no worse off than owning a conventional vehicle after the second year were most sensitive to battery capacity/AER. Battery degradation costs were most insensitive to charging level. Net annual costs were robust against both charging level and DOD. Hourly payments across all customer groups were most insensitive to charging regime.

Figure 8 illustrates the impact of connection time and battery degradation costs on hourly payments. In Figure 8a, hourly payments decrease as a power law with increasing connection time $\left(\mathrm{R}^{2}>0.60\right)$. Both connection time and total vehicle number, illustrated in Figure 8b and c, respectively, were most dependent on end of life capacity fade. Likewise, they were most insensitive to charging level (and independent of battery cost).

The UK fleet of EV grew by (a median) 23\% annually from 1994 to 2013 [? 11. Opportunistic charging with DOD to $80 \%$ required the smallest fleet of $23,400 \mathrm{EV}$ to provide firm fast reserve. Opportunistic charging with end of life criterion relaxed to $70 \%$ required the largest fleet of $149,000 \mathrm{EV}$ to meet firm fast reserve requirements. In the best case, such an EV fleet would be in service in the year 2019; in the worst case, by 2028 using the observed $23 \%$ annual growth compounded, as shown in black asterisks in Figure 9. This projection is optimistic because it relies on four assumptions: first, that the median growth rate

\footnotetext{
${ }^{11}$ This analysis is based in 2013 to maintain consistency across all inputs. Latest data shows 16,200 EV were sold in 2014. The influence of this jump in EV sales is to increase the median annual growth rate from $23 \%$ to $25 \%$.
} 
continues; second, all of the vehicle owners choose to participate in V2G; third, the large gaps between cost of ownership and rewards accrued from V2G participation are closed; and fourth, that no EV are retired from the fleet. Finally, achieving a fleet under these assumptions leads to firm fast reserve provided for a median $0.42 \mathrm{~h}$, up to $2.7 \mathrm{~h}$ per day, starting at $1900 \mathrm{~h}$ for both opportunistic and charging at home only and at $0930 \mathrm{~h}$ when charging at work only. Therefore, the fleet must be larger still to increase the number and duration of connection periods to enable participation in an all-day, everyday ancillary services market. A recent survey of industry perspectives [? ] echoes these findings, suggesting that V2G will be a long term prospect on account of the time required to achieve a large enough EV fleet, both to meet V2G grid requirements and justify the investment in infrastructure.

\section{Conclusion}

Often, it is suggested that the energy and capacity payments from providing V2G ancillary services can reduce EV ownership costs which acts as an incentive for prospective EV purchasers. This work has investigated this attractiveness to these consumer groups separately. On the one hand, the existing EV owner should receive payments to cover additional battery degradation costs associated with providing firm fast reserve over the vehicle lifetime. On the other, a prospective EV owner will be comparing costs to a conventional vehicle and will want to recover any excess within two years, in general.

An EV being driven on the NEDC and not participating in V2G has a battery lifetime of 12 years because the daily energy throughput is $0.93 \mathrm{Ah}$ and battery state of charge does not drop below $98 \%$. Providing firm fast reserve leads to daily discharges of $30 \%$ and energy throughout of $122 \mathrm{Ah}$. Therefore, battery life shortens to 1.7 years. The existing or prospective EV owner would be expected to meet the costs of battery replacement under traditional vehicle ownership models. A vehicle aggregator is required to pool vehicles to meet the UK National Grid firm fast reserve requirements of $50 \mathrm{MW}$ for 15-minutes. In 2013, the aggregator would likely receive a capacity payment of $£ 805$ per hour the fleet was connected to the grid.

Across all scenarios, providing V2G ancillary services is unattractive to either existing or prospective EV owners. In most cases, the fleets are connected from $1900 \mathrm{~h}$ for 0.42 hours, up to 2.7 hours. At most, the aggregator would receive $£ 2,100$. However, a minimum of $23,400 \mathrm{EV}$ ( $\mathrm{DOD}=80 \%$ ) are required to meet the firm fast reserve requirements, up to $149,000 \mathrm{EV}$ when end of life criterion is relaxed to $70 \%$ capacity fade. Therefore, the aggregator may only have $£ 0.004-0.034$ to pay out to each vehicle based on its capacity payments from the grid. However, existing EV owners need hourly payments of at least £0.35 (end of life capacity fade criterion of $60 \%$ ) up to $£ 105$ (battery costs of $£ 800 \mathrm{kWh}^{-1}$ ) to recover the costs due to battery degradation to leave them no worse off than if they did not provide V2G services. Therefore, likely disbursements from the aggregator are 20-14,000 times lower than what each vehicle owner would need.

Similarly, prospective EV owners need at least $£ 5$ per hour (battery capacity of $12 \mathrm{kWh}$ ) up to 160 


\section{Acknowledgements}

The authors acknowledge the funding provided for this work by the Oxford Martin School.

\section{References}

[1] C. Zhou, K. Qian, M. Allan, W. Zhou, Modeling of the Cost of EV Battery Wear Due to V2G Application in Power Systems, IEEE Transactions on Energy Conversion 26 (4) (2011) 1041-1050. doi:10.1109/TEC.2011.2159977

[2] G. R. Parsons, M. K. Hidrue, W. Kempton, M. P. Gardner, Willingness to pay for vehicle-to-grid (V2G) electric vehicles and their contract terms, Energy Economics 42 (2014) 313-324. doi:10.1016/j.eneco.2013.12.018

[3] S. B. Peterson, J. F. Whitacre, J. Apt, The economics of using plug-in hybrid electric vehicle battery packs for grid storage, Journal of Power Sources 195 (8) (2010) 2377-2384. doi:10.1016/j.jpowsour.2009.09.070

[4] U. Chukwu, S. Mahajan, V2G electric power capacity estimation and ancillary service market evaluation, in: IEEE Power and Energy Society (PES) General Meeting, San Diego, 2011, pp. 1-8. doi:10.1109/PES.2011.6039703 
[5] H. Lund, W. Kempton, Integration of renewable energy into the transport and electricity sectors through V2G, Energy Policy 36 (9) (2008) 3578-3587. doi:10.1016/j.enpol.2008.06.007

[6] A. Millner, N. Judson, B. Ren, E. Johnson, W. Ross, Enhanced plug-in hybrid electric vehicles, in: IEEE Conference on Innovative Technologies for an Efficient and Reliable Electricity Supply (CITRES), Waltham, 2010, pp. 333-340. doi:10.1109/CITRES.2010.5619783

[7] T. Ghanbarzadeh, P. Baboli, M. Rostami, M. Moghaddam, M. Sheikh-El-Eslami, Wind farm power management by high penetration of PHEV, in: IEEE Power and Energy Society (PES) General Meeting, San Diego, 2011, pp. 1-5. doi:10.1109/PES.2011.6039902

[8] J. Tomić, W. Kempton, Using fleets of electric-drive vehicles for grid support, Journal of Power Sources 168 (2) (2007) 3578-3587. doi:10.1016/j.jpowsour.2007.03.010

[9] C. D. White, K. M. Zhang, Using vehicle-to-grid technology for frequency regulation and peak-load reduction, Journal of Power Sources 196 (8) (2011) 3972-3980. doi:10.1016/j.jpowsour.2010.11.010

[10] NG, Fast Reserve Service Description 2013 National Grid, 2013. URL http://www2 .nationalgrid.com/WorkArea/DownloadAsset . aspx?id=41297

[11] NG, Mandatory Frequency Response, National Grid, 2013.

[12] S. B. Peterson, J. Apt, J. F. Whitacre, Lithium-ion battery cell degradation resulting from realistic vehicle and vehicleto-grid utilization, Journal of Power Sources 195 (8) (2010) 2385-2392. doi:10.1016/j.jpowsour.2009.10.010

[13] S. Sarabi, A. Bouallaga, A. Davigny, B. Robyns, V. Courtecuisse, Y. Riffonneau, M. Régner, The Feasibility of the Ancillary Services for Vehicle-to-Grid Technology in: $11^{\text {th }}$ International Conference on the European Energy Market, Krakow, 2014. URL http://ieeexplore.ieee.org/stamp/stamp.jsp?arnumber=6861251

[14] T. Markel, M. Kuss, P. Denholm, Communication and control of electric drive vehicles supporting renewables, in: IEEE Vehicle Power and Propulsion Conference (VPPC), Dearborn, 2009, pp. 27-34. doi:10.1109/VPPC.2009.5289874

[15] J. D. K. Bishop, C. J. Axon, D. Bonilla, M. Tran, D. Banister, M. D. McCulloch, Evaluating the impact of V2G services on the degradation of batteries in PHEV and EV, Applied Energy 111 (2013) 206-218. doi:10.1016/j.apenergy.2013. 04.094

[16] B. Lunz, Z. Yan, J. B. Gerschler, D. U. Sauer, Influence of plug-in hybrid electric vehicle charging strategies on charging and battery degradation costs, Energy Policy 46 (2012) 511-519. doi:10.1016/j.enpol.2012.04.017.

[17] NMC, Annual Report 2014. Nissan Motor Company, 2014.

URL www.nissan-global.com/EN/DOCUMENT/PDF/AR/2014/AR2014_E_All.pdf

[18] A. Santos, N. McGuckin, H. Y. Nakamoto, D. Gray, S. Liss, Summary of Travel Trends: 2009 National Household Travel Survey no. FHWA-PL-11-022, US Department of Transportation Federal Highway Administration, Washington DC, USA, 2011.

URL http://nhts.ornl.gov/2009/pub/stt.pdf

[19] DfT, National Travel Survey: Statistical Release Department for Transport, London, 2014.

URL https://www.gov.uk/government/collections/national-travel-survey-statistics

[20] T. Markel, et al., ADVISOR: a systems analysis tool for advanced vehicle modelling, Journal of Power Sources 110 (2) (2002) 255-266. doi:10.1016/S0378-7753(02)00189-1.

[21] J. Wang, P. Liu, J. Hicks-Garner, E. Sherman, S. Soukiazian, M. Verbrugge, H. Tataria, J. Musser, P. Finamore, Cycle-life model for graphite-LiFePO 4 cells, Journal of Power Sources 196 (8) (2011) 3942-3948. doi:10.1016/j.jpowsour.2010. 11.134

[22] DfT, Transport Statistics Great Britain United Kingdom Department for Transport, London, 2014.

URL https://www.gov.uk/government/uploads/system/uploads/attachment_data/file/389596/ 
tsgb-2014-print-ready-version.pdf

[23] J. King, The King Review of low-carbon cars (Part I: the potential for $\mathrm{CO}_{2}$ reduction), HM Treasury, 2007.

[24] D. Howell, Battery Status and Cost Reduction Prospects, in: EV Everywhere Grand Challenge: Battery Workshop, Chicago, 2012.

URL http://www1.eere.energy.gov/vehiclesandfuels/pdfs/ev_everywhere/5_howell_b.pdf

[25] IEA, Technology Roadmap: Electric and plug-in hybrid electric vehicles, International Energy Agency, Paris, 2011. URL http://www.iea.org/publications/freepublications/publication/EV_PHEV_Roadmap.pdf

[26] K. C. Divya, J. Østergaard, Battery energy storage technology for power systems-an overview, Electric Power Systems Research 79 (4) (2009) 511-520. doi:10.1016/j.epsr.2008.09.017.

[27] B. Nykvist, M. Nilsson, Rapidly falling costs of battery packs for electric vehicles, Nature Climate Change 5 (2015) 329-332. doi:10.1038/nclimate2564.

[28] S. Saxena, C. L. Floch, J. MacDonald, S. Moura, Quantifying EV battery end-of-life through analysis of travel needs with powertrain models, Journal of Power Sources 282 (2015) 265-276. doi:10.1016/j.jpowsour.2015.01.072

[29] C. Weiller, A. Neely, Using electric vehicles for energy services: Industry perspectives, Energy 77 (2014) 194-200. doi: $10.1016 / j$. energy.2014.06.066 
Table 1: Specifications of Nissan LEAF used in the ADVISOR model

\begin{tabular}{|l|c|}
\hline Glider mass $(\mathrm{kg})$ & 1175 \\
Kerb mass $(\mathrm{kg})$ & 1538 \\
Coefficient of drag & 0.29 \\
Frontal area $\left(\mathrm{m}^{2}\right)$ & 2.27 \\
Wheel diameter $(\mathrm{m})$ & 0.20 \\
Peak motor power $(\mathrm{kW})$ & 80 \\
Peak motor torque $(\mathrm{Nm})$ & 280 \\
Energy use on the NEDC $\left(\mathrm{Wh} \mathrm{km}^{-1}\right)$ & 150 \\
\hline
\end{tabular}

\section{List of tables}


Table 2: Revenues and costs associated with operating an EV fleet which is providing firm fast reserve in the base case.

\begin{tabular}{|l|c|}
\hline Base case & \\
\hline Start time (h) & 19 \\
Hours available & 0.42 \\
Vehicle number (total) & 44299 \\
- power level & 44299 \\
- power duration & 0 \\
\hline \hline Revenues to the fleet aggregator & \\
Energy (£) & 1753 \\
Capacity $(£)$ & 335 \\
Revenue available per vehicle $(£)$ & 0.008 \\
\hline \hline Cost to each EV owner & \\
Battery degradation costs $\left(£ \mathrm{~km}^{-1}\right)$ & 0.17 \\
Annual net costs $(£)$ & -10856 \\
Battery lifetime (years) & 1.7 \\
\hline \hline Compensation required each EV owner to cover costs & \\
Hourly payments $\left(£ \mathrm{~h}^{-1}\right.$ ) & \\
- NPV EV with no V2G & 37 \\
- NPV conventional vehicle over lifetime & 52 \\
- NPV conventional vehicle by year 2 & 64 \\
\hline
\end{tabular}




\section{Figure captions}

1. Schematic of revenue gap which needs to be filled by firm fast reserve capacity payments for a) the existing EV owner to be left no worse off than if there was no participation in V2G by the end of the vehicle lifetime (vertical arrow at year 8); the prospective EV owner to be left no worse off financially than the owner of a conventional vehicle (blue solid) after two years (purple arrow) by the end of the vehicle lifetime (green arrow). The EV with no V2G and providing firm fast reserve incorporating energy payments only is shown by a red solid and yellow solid lines, respectively.

2. Summary of the impact of AER on: a) battery degradation cost per km travelled; b) annual payments; c) total number of vehicles in the fleet required to meet the power (blue) and duration (yellow) requirements of firm fast reserve; and d) the hourly payments due to existing EV owners (blue), prospective EV owners wishing to recover costs over the vehicle lifetime (green) and prospective EV owners wishing to recover costs within two years (yellow).

3. Probability of the vehicle driving (blue, solid) or stationary and available to supply V2G services at work only (green, dashed) or at home only (black, dashed) in a 24-hour period.

4. Summary of the impact of individual vehicle battery DOD on: a) battery degradation cost per $\mathrm{km}$ travelled; b) annual payments; c) total number of vehicles in the fleet required to meet the power (blue) and duration (yellow) requirements of firm fast reserve; and d) the hourly payments due to existing EV owners (blue), prospective EV owners wishing to recover costs over the vehicle lifetime (green) and prospective EV owners wishing to recover costs within two years (yellow).

5. Summary of the impact of charging level on: a) battery degradation cost per km travelled; b) annual payments; c) total number of vehicles in the fleet required to meet the power (blue) and duration (yellow) requirements of firm fast reserve; and d) the hourly payments due to existing EV owners (blue), prospective EV owners wishing to recover costs over the vehicle lifetime (green) and prospective EV owners wishing to recover costs within two years (yellow). Key for charging levels: $1=\mathrm{L} 1 / \mathrm{L} 1 ; 2$ $=\mathrm{L} 2 / \mathrm{L} 2 ; 3=\mathrm{L} 3 / \mathrm{L} 3 ; 4=\mathrm{L} 1 / \mathrm{L} 2 ; 5=\mathrm{L} 1 / \mathrm{L} 3 ; 6=\mathrm{L} 2 / \mathrm{L} 1 ;$ and $7=\mathrm{L} 3 / \mathrm{L} 1$.

6. Summary of the impact of EOL criterion on: a) battery degradation cost per km travelled; b) annual payments; c) total number of vehicles in the fleet required to meet the power (blue) and duration (yellow) requirements of firm fast reserve; and d) the hourly payments due to existing EV owners (blue), prospective EV owners wishing to recover costs over the vehicle lifetime (green) and prospective EV owners wishing to recover costs within two years (yellow).

7. Summary plot of the range of sensitivities of a) battery degradation cost per km travelled; b) annual payments; c) hourly payments required by each EV; d) capacity payment gap for the EV for V2G ancillary services and across the sensitivity tests of: i. charging regime; ii. battery capacity and AER; iii. DOD for firm fast reserve; iv. battery cost; v. charging level; and vi. end of life criterion. For 
subplots c) and d): blue represents the two year time horizon; red, the asset life; and yellow, the gap between lifetime costs of an EV with and without participation in firm fast reserve.

8. Comparison of hourly payments to the individual vehicles with required fleet size to meet firm fast reserve requirements of $50 \mathrm{MW}$ for 15-minutes. a) hourly payments per vehicle as a function of connection time, where bubble size is proportion to total vehicle fleet number; b) summary plot of the range of sensitivities of connection time by sensitivity test; and c) summary plot of the range of sensitivities of total fleet number by sensitivity test. Blue, yellow and red series in a) represent hourly payments to existing EV owners, to prospective EV owners over the vehicle lifetime and within two years, respectively.

9. EV sales in the UK from 1994 to 2013 (blue) and projection sales using median growth rate compounded annually (orange). Black asterisks indicate the years in which the smallest and largest electric vehicle fleet size is achieved: 2019 for the best case of 23,400; and 2028 for the worst case of 149,000. 


\section{List of figures}

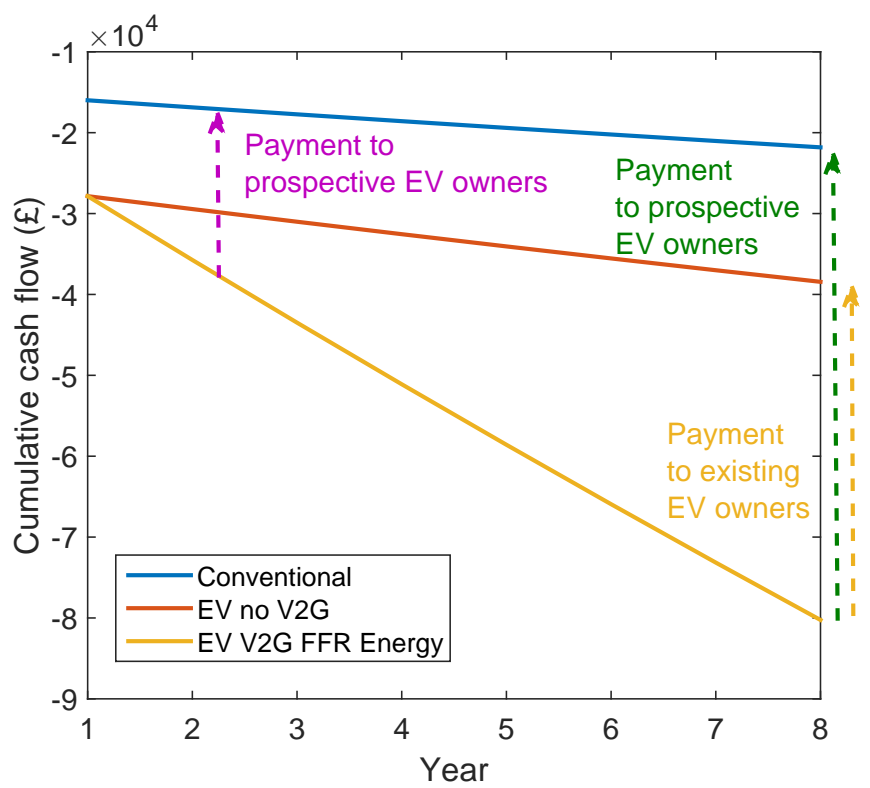


a)

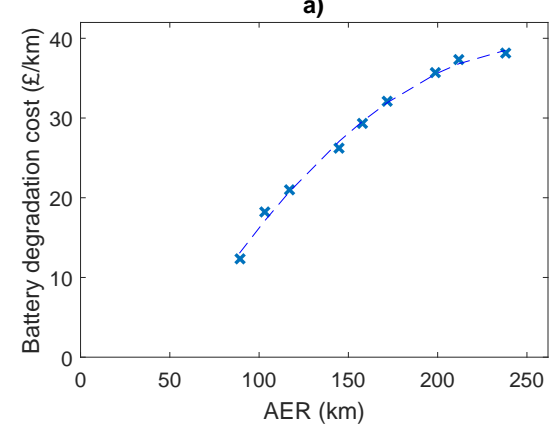

c)

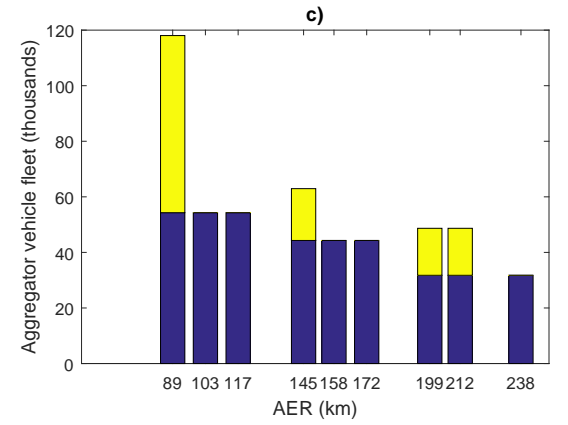

b)

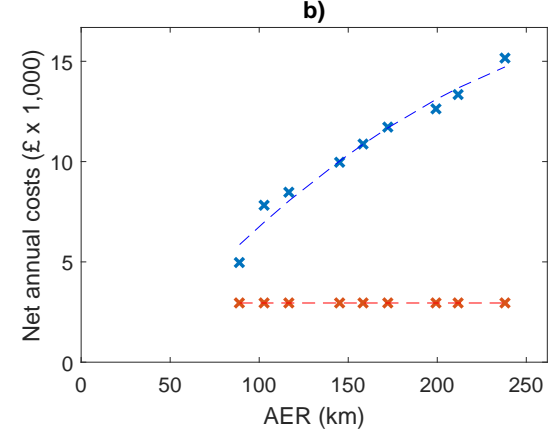

d)

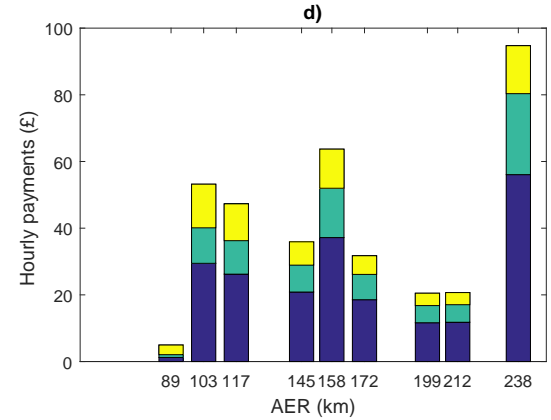

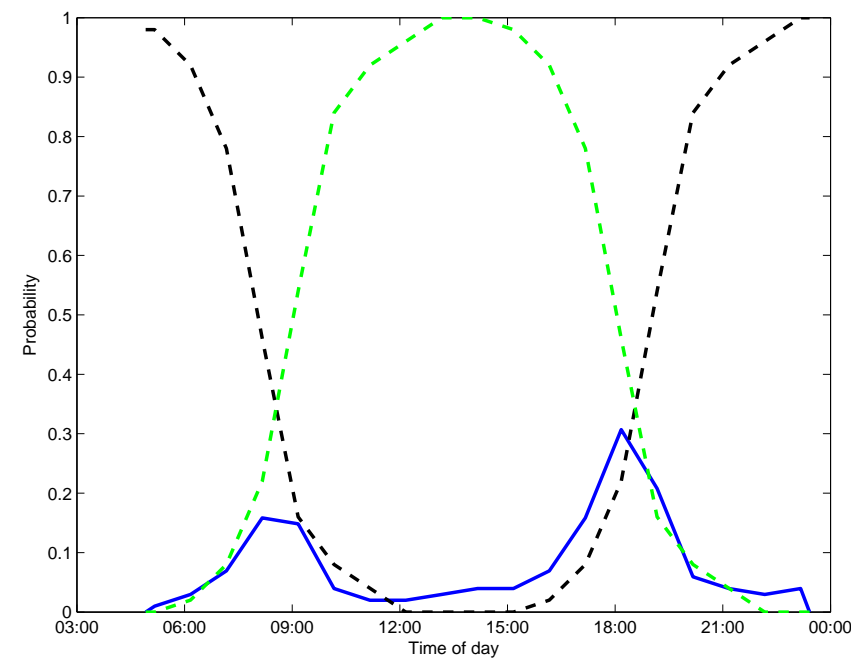


a)

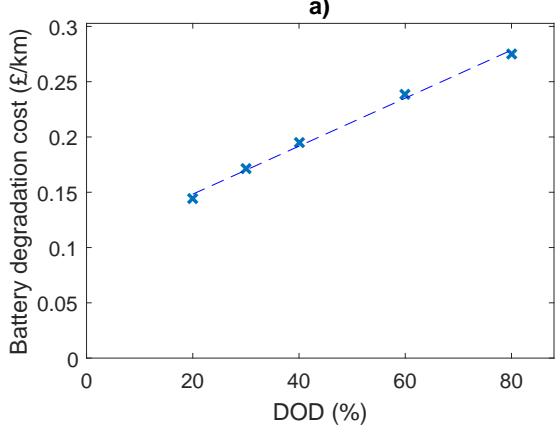

c)

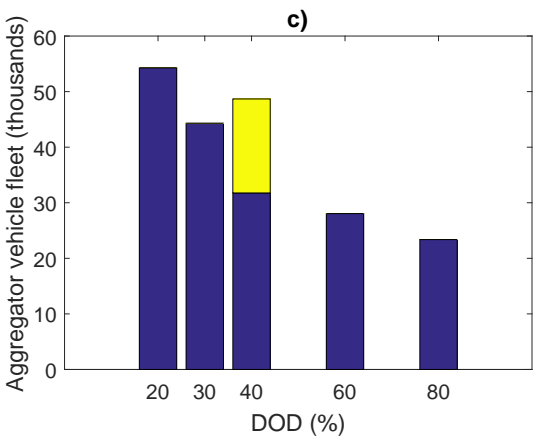

a)

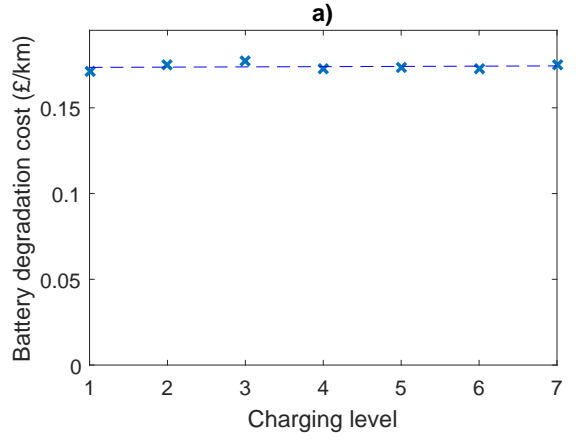

c)

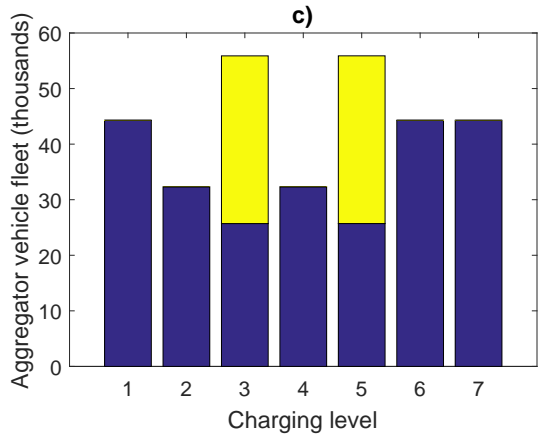

b)

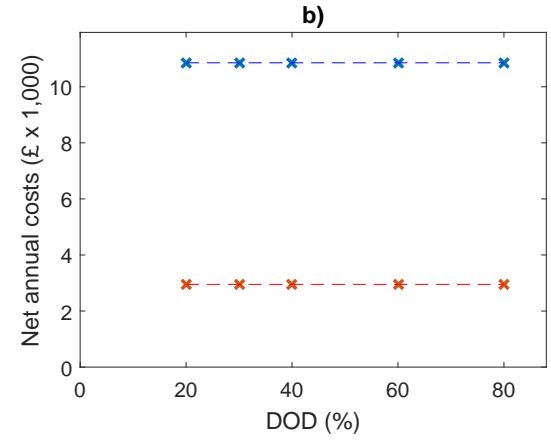

d)

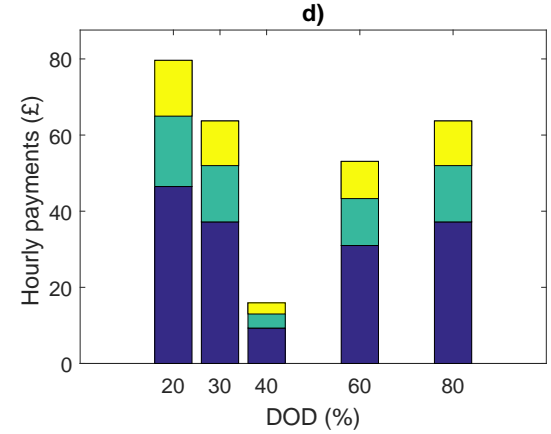

b)

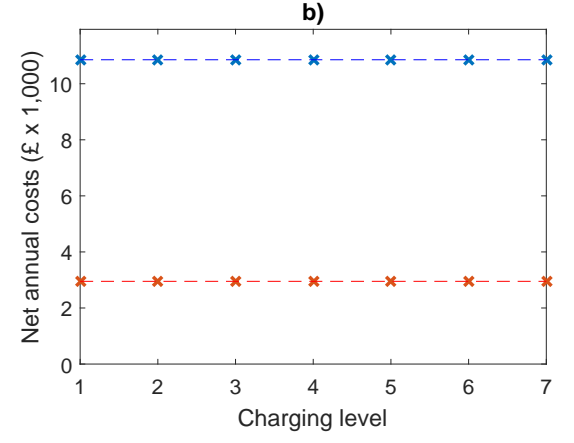

d)

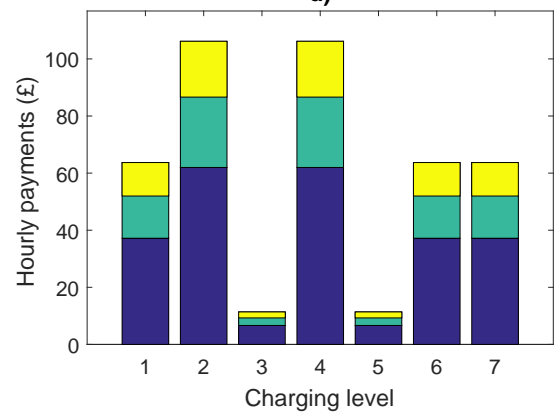


a)
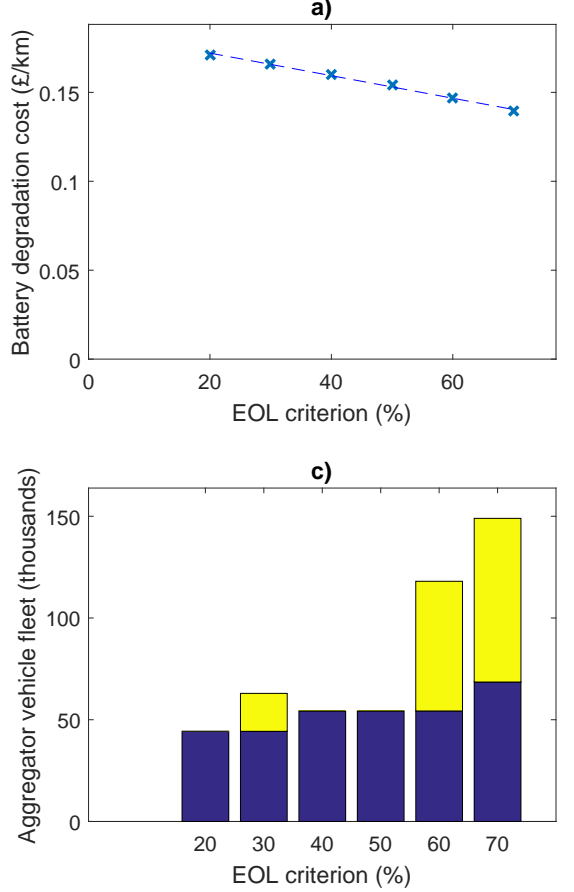

b)

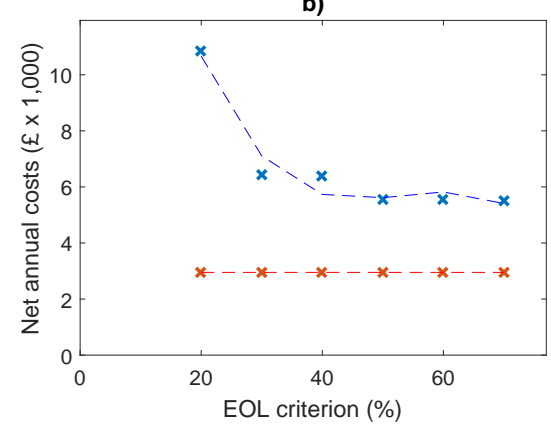

d)

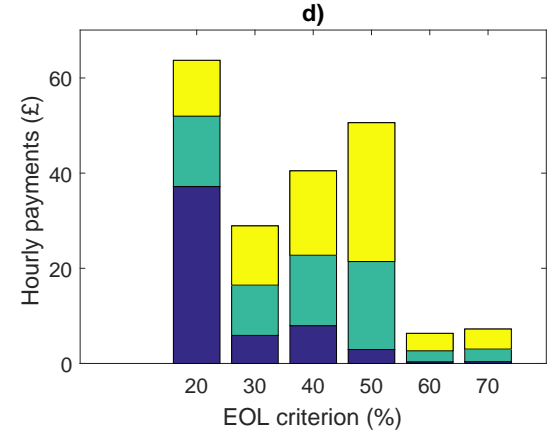

Appendix A. Supplementary tables of results 
a)

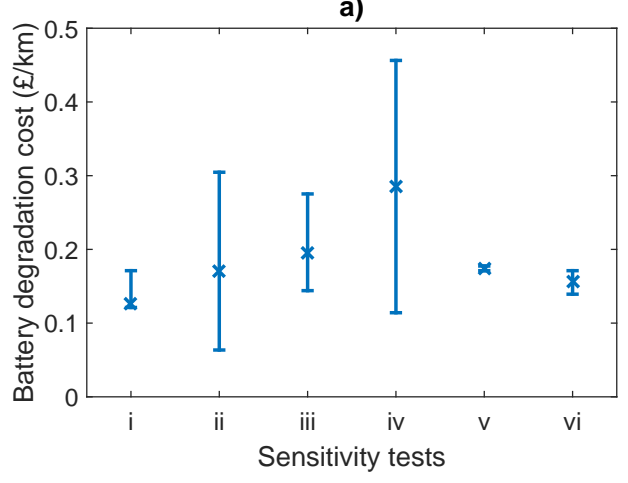

c)

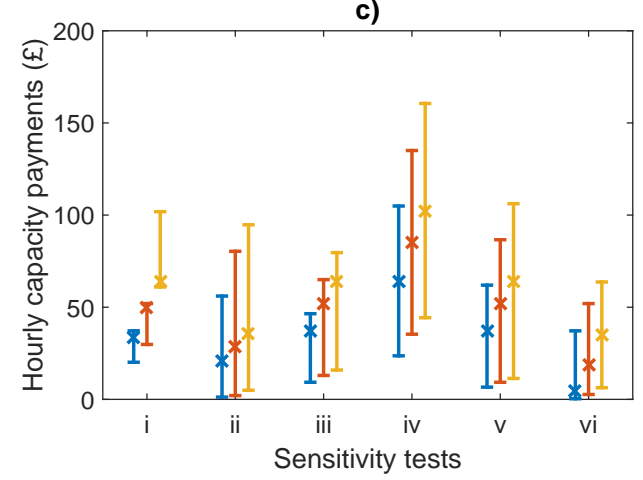

b)

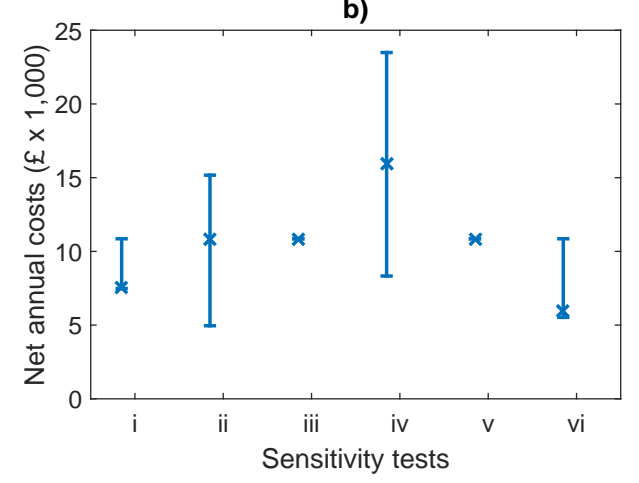

d)

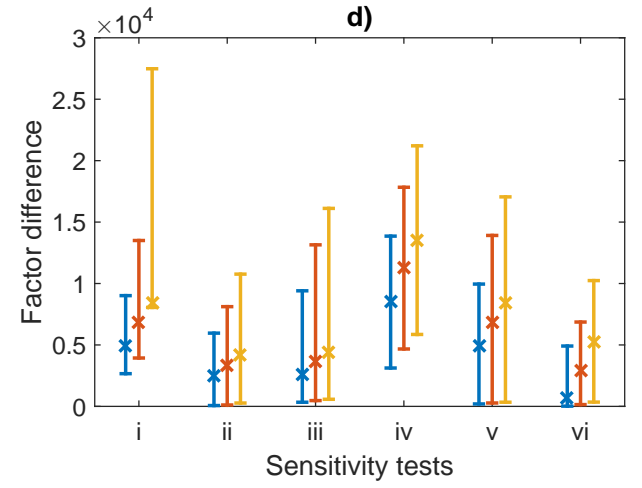




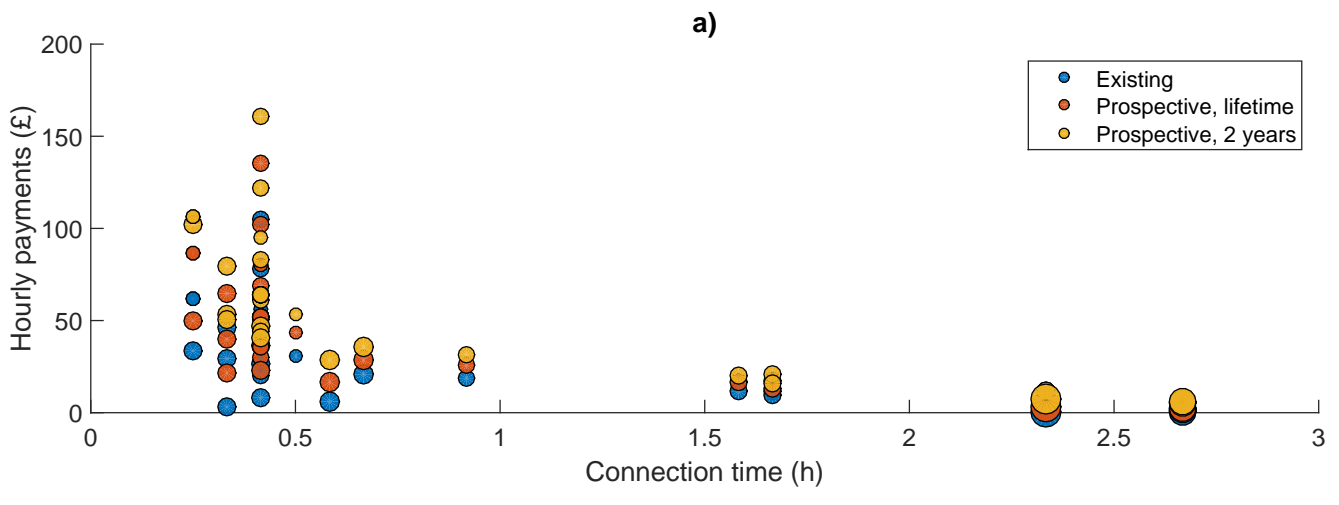

b)
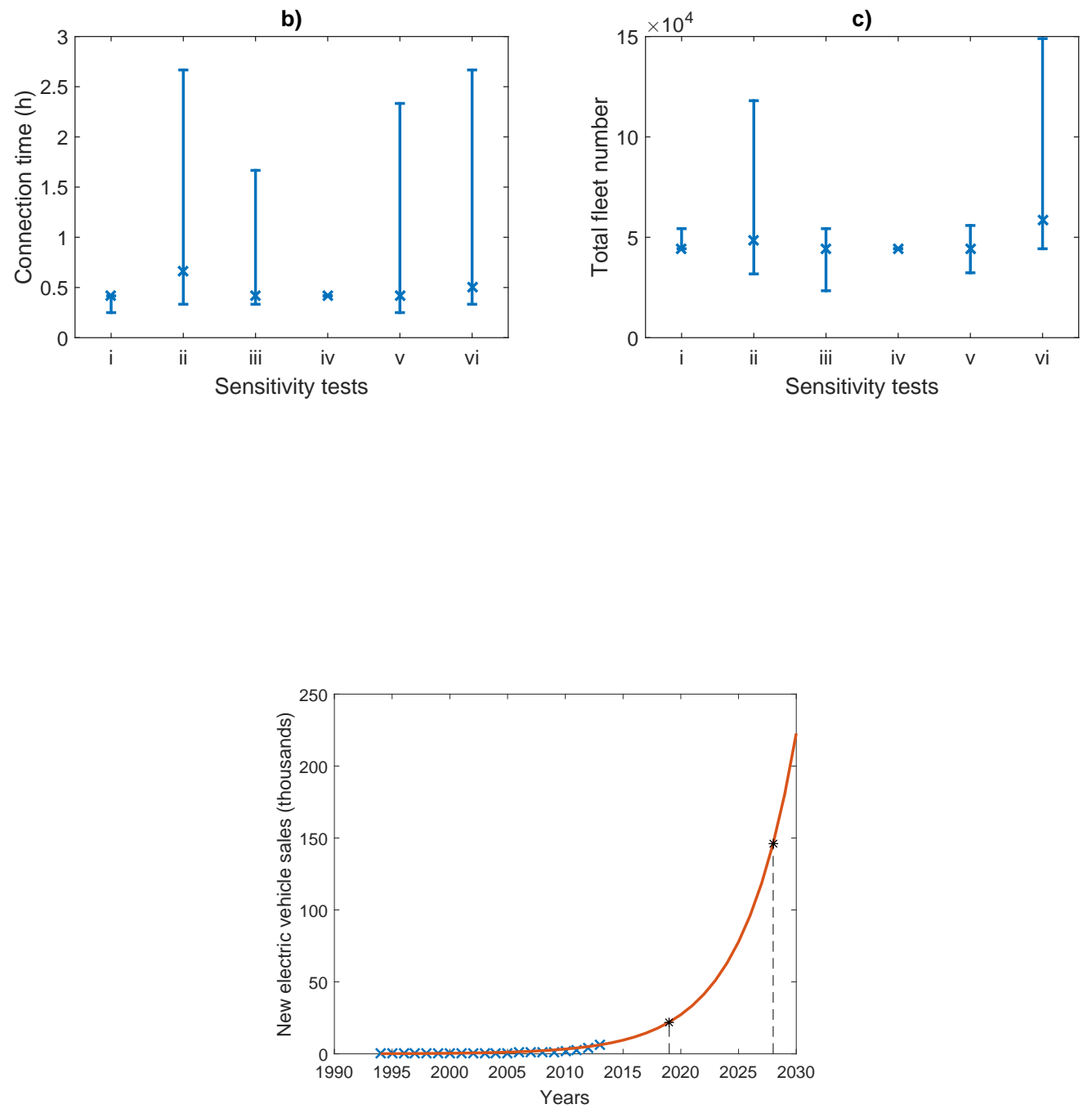


\begin{tabular}{|c|c|c|c|c|c|c|c|c|c|c|c|c|}
\hline 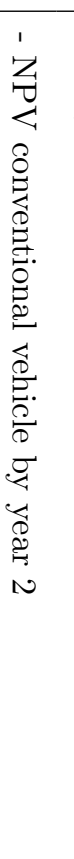 & 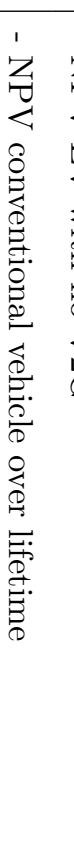 & 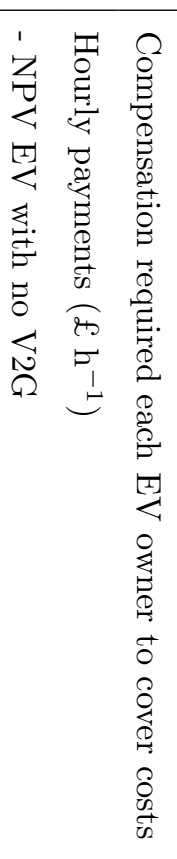 & 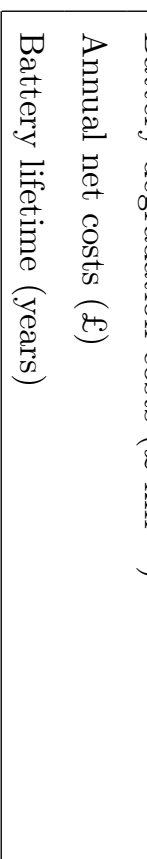 & 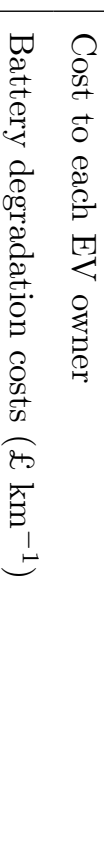 & 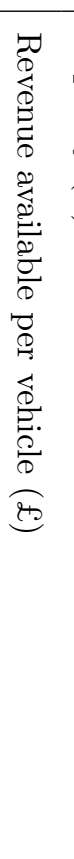 & कृ & 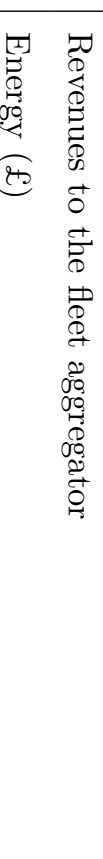 & 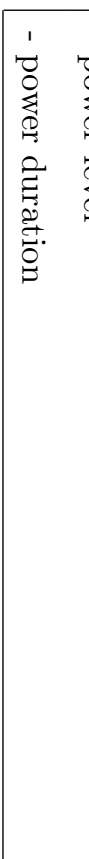 & 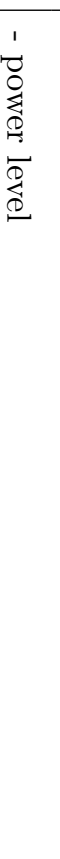 & 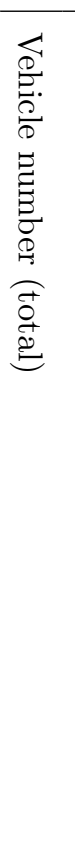 & 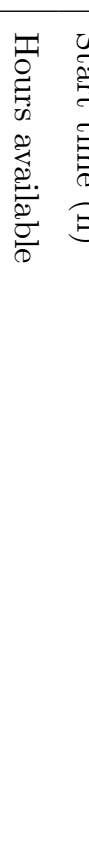 & 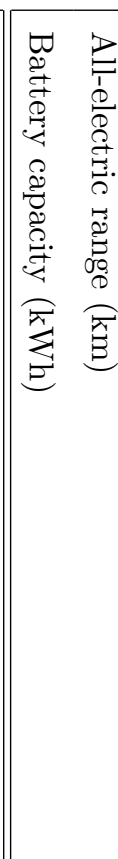 \\
\hline or & $N$ & $\vdash$ & 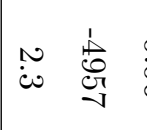 & ஜ & $\stackrel{\ominus}{\infty}$ & 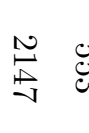 & & | & 䶮 & 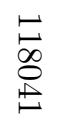 & $\begin{array}{ll}\stackrel{0}{0} & 8 \\
\dot{v} & 8\end{array}$ & $\vec{N}$ \\
\hline ఝ & B & ஸ્ & $N \underset{\substack{1 \\
0 \\
0 \\
0}}{0}$ & P & $\begin{array}{l}\stackrel{\circ}{\dot{c}} \\
\dot{c}\end{array}$ & 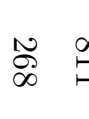 & & 0 & 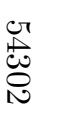 & 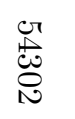 & $\stackrel{0}{\dot{d u}}$ & $\sigma \quad \overrightarrow{0}$ \\
\hline$\stackrel{\Delta}{\Delta}$ & $\stackrel{\infty}{\sigma}$ & 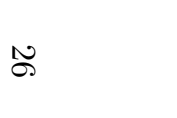 & 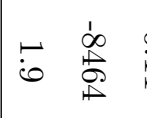 & $\dot{\ominus}$ & : & لٌ & & 0 & 柋 & 蛋 & $\stackrel{0}{\stackrel{0}{N}}$ & $\infty \underset{\nu}{ }$ \\
\hline 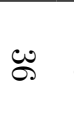 & చి & $\stackrel{N}{\sim}$ & 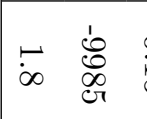 & $\stackrel{\circ}{\dot{c}}$ & : & $\underset{d}{d}$ & & 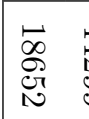 & 莽 & 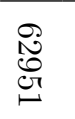 & $\dot{9}$ & હ怎 \\
\hline$\stackrel{\perp}{\perp}$ & G & $\stackrel{v}{v}$ & 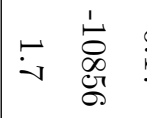 & $\stackrel{\circ}{\ominus}$ & $\begin{array}{l}\dot{8} \\
\dot{\infty}\end{array}$ & Dِ & & $\circ$ & 毞 & 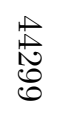 & $\begin{array}{l}\dot{P} \\
\dot{A}\end{array}$ & 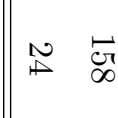 \\
\hline 芯 & 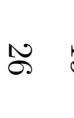 & $\vec{\bullet}$ & $\dot{\sigma} \stackrel{\vec{\sigma}}{\overrightarrow{0}}$ & $\stackrel{0}{0}$ & 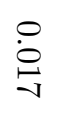 & $\underset{\infty}{\vec{D}}$ & & $\circ$ & 莣 & 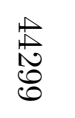 & $\begin{array}{l}0 \\
\dot{0} \\
i\end{array}$ & $\stackrel{\sim}{\triangle}$ \\
\hline 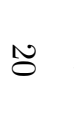 & $\sqsupset$ & ஸ & 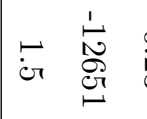 & ني & 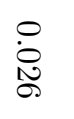 & $\begin{array}{ll}\vec{N} & 0 \\
\vec{J} & d \\
\mathcal{H} & \end{array}$ & & $\begin{array}{l}\vec{b} \\
\stackrel{6}{\sigma}\end{array}$ & 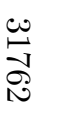 & $\begin{array}{l}\infty \\
\infty \\
\stackrel{2}{9} \\
\infty\end{array}$ & $\stackrel{\vec{c}}{\dot{c}}$ & $\ddot{\theta}$ \\
\hline$\stackrel{N}{\bullet}$ & $\vec{v}$ & ウ & ن. & 怘 & $\begin{array}{l}\stackrel{0}{\infty} \\
\stackrel{\infty}{\infty}\end{array}$ & 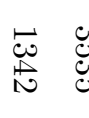 & & 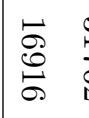 & 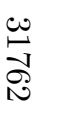 & $\begin{array}{l}1 \\
\infty \\
\stackrel{\infty}{9} \\
\infty \\
\infty\end{array}$ & $\vec{g}$ & 品 \\
\hline ci & $\infty$ & gु & 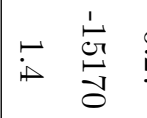 & $\underset{i}{i}$ & $\begin{array}{l}\dot{0} \\
\dot{\Xi}\end{array}$ & 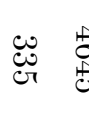 & & 0 & 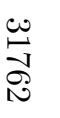 & 岕 & $\stackrel{\circ}{i}$ & $\ddot{~}$ \\
\hline
\end{tabular}


Table A.4: Revenues and costs associated with operating an EV fleet which is providing firm fast reserve by charging opportunistically, at home only and at work only.

\begin{tabular}{|c|c|c|c|}
\hline Charging regime & Opportunistic & Home only & Work only \\
\hline Start time $(\mathrm{h})$ & 1900 & 1900 & 0930 \\
\hline Hours available & 0.42 & 0.42 & 0.25 \\
\hline Vehicle number (total) & 44299 & 44299 & 54302 \\
\hline - power level & 44299 & 44299 & 54302 \\
\hline - power duration & 0 & 0 & 0 \\
\hline \multicolumn{4}{|l|}{ Revenues to the fleet aggregator } \\
\hline Energy $(£)$ & 1753 & 1091 & 1180 \\
\hline Capacity $(£)$ & 335 & 335 & 201 \\
\hline Revenue available per vehicle $(£)$ & 0.008 & 0.008 & 0.004 \\
\hline \multicolumn{4}{|l|}{ Cost to each EV owner } \\
\hline Battery degradation costs $\left(£ \mathrm{~km}^{-1}\right)$ & 0.17 & 0.12 & 0.13 \\
\hline Annual net costs $(£)$ & -10856 & -7484 & -7517 \\
\hline Battery lifetime (years) & 1.7 & 2.4 & 2.3 \\
\hline \multirow{2}{*}{\multicolumn{4}{|c|}{$\begin{array}{l}\text { Compensation required each EV owner to cover costs } \\
\text { Hourly payments }\left(£ h^{-1}\right)\end{array}$}} \\
\hline & & & \\
\hline - NPV EV with no V2G & 37 & 20 & 33 \\
\hline - NPV conventional vehicle over lifetime & 52 & 30 & 50 \\
\hline - NPV conventional vehicle by year 2 & 64 & 61 & 102 \\
\hline
\end{tabular}


Table A.5: Revenues and costs associated with operating an EV fleet which is providing firm fast reserve by charging opportunistically and across a $20-80 \%$ range of depth of discharges.

\begin{tabular}{|l|c|c|c|c|c|}
\hline Depth of discharge (\%) & 20 & 30 & 40 & 60 & 80 \\
\hline Start time (h) & 1900 & 1900 & 1900 & 2000 & 2000 \\
Hours available & 0.33 & 0.42 & 1.67 & 0.5 & 0.42 \\
Vehicle number (total) & 54302 & 44299 & 48678 & 28057 & 23381 \\
- power level & 54302 & 44299 & 31762 & 28057 & 23381 \\
- power duration & 0 & 0 & 16916 & 0 & 0 \\
\hline \hline Revenues to the fleet aggregator & & & & & \\
Energy (£) & 1753 & 1753 & 1753 & 1753 & 1753 \\
Capacity (£) & 268 & 335 & 1342 & 403 & 335 \\
Revenue available per vehicle (£) & 0.005 & 0.008 & 0.028 & 0.014 & 0.014 \\
\hline \hline Cost to each EV owner & & & & & \\
Battery degradation costs (£ km ${ }^{-1}$ ) & 0.14 & 0.17 & 0.2 & 0.24 & 0.28 \\
Annual net costs (£) & -10856 & -10856 & -10856 & -10856 & -10856 \\
Battery lifetime (years) & 2 & 1.7 & 1.5 & 1.2 & 1 \\
\hline \hline Compensation required each EV owner to cover costs & & & & & \\
Hourly payments (£ ${ }^{-1}$ ) & & & & & \\
- NPV EV with no V2G & 46 & 37 & 9 & 31 & 37 \\
- NPV conventional vehicle over lifetime & 65 & 52 & 13 & 43 & 52 \\
- NPV conventional vehicle by year 2 & 80 & 64 & 16 & 53 & 64 \\
\hline
\end{tabular}


Table A.6: Revenues and costs associated with operating an EV fleet which is providing firm fast reserve by charging opportunistically and across a $£ 200-800 \mathrm{kWh}^{-1}$ range of battery costs.

\begin{tabular}{|l|c|c|c|c|}
\hline Battery cost $\left(£ \mathrm{kWh}^{-1}\right)$ & 200 & 400 & 600 & 800 \\
\hline Start time (h) & 1900 & 1900 & 1900 & 1900 \\
Hours available & 0.42 & 0.42 & 0.42 & 0.42 \\
Vehicle number (total) & 44299 & 44299 & 44299 & 44299 \\
- power level & 44299 & 44299 & 44299 & 44299 \\
- power duration & 0 & 0 & 0 & 0 \\
\hline \hline Revenues to the fleet aggregator & & & & \\
Energy (£) & 1753 & 1753 & 1753 & 1753 \\
Capacity (£) & 335 & 335 & 335 & 335 \\
Revenue available per vehicle $(£)$ & 0.008 & 0.008 & 0.008 & 0.008 \\
\hline \hline Cost to each EV owner & & & & \\
Battery degradation costs $(£ ~ k m-1)$ & 0.11 & 0.23 & 0.34 & 0.45 \\
Annual net costs $(£)$ & -8329 & -13382 & -18434 & -23487 \\
Battery lifetime (years) & 1.7 & 1.7 & 1.7 & 1.7 \\
\hline \hline Compensation required each EV owner to cover costs & & & & \\
Hourly payments (£ h ${ }^{-1}$ ) & & & & \\
- NPV EV with no V2G & 24 & 51 & 78 & 105 \\
- NPV conventional vehicle over lifetime & 35 & 69 & 102 & 135 \\
- NPV conventional vehicle by year 2 & 44 & 83 & 122 & 161 \\
\hline
\end{tabular}




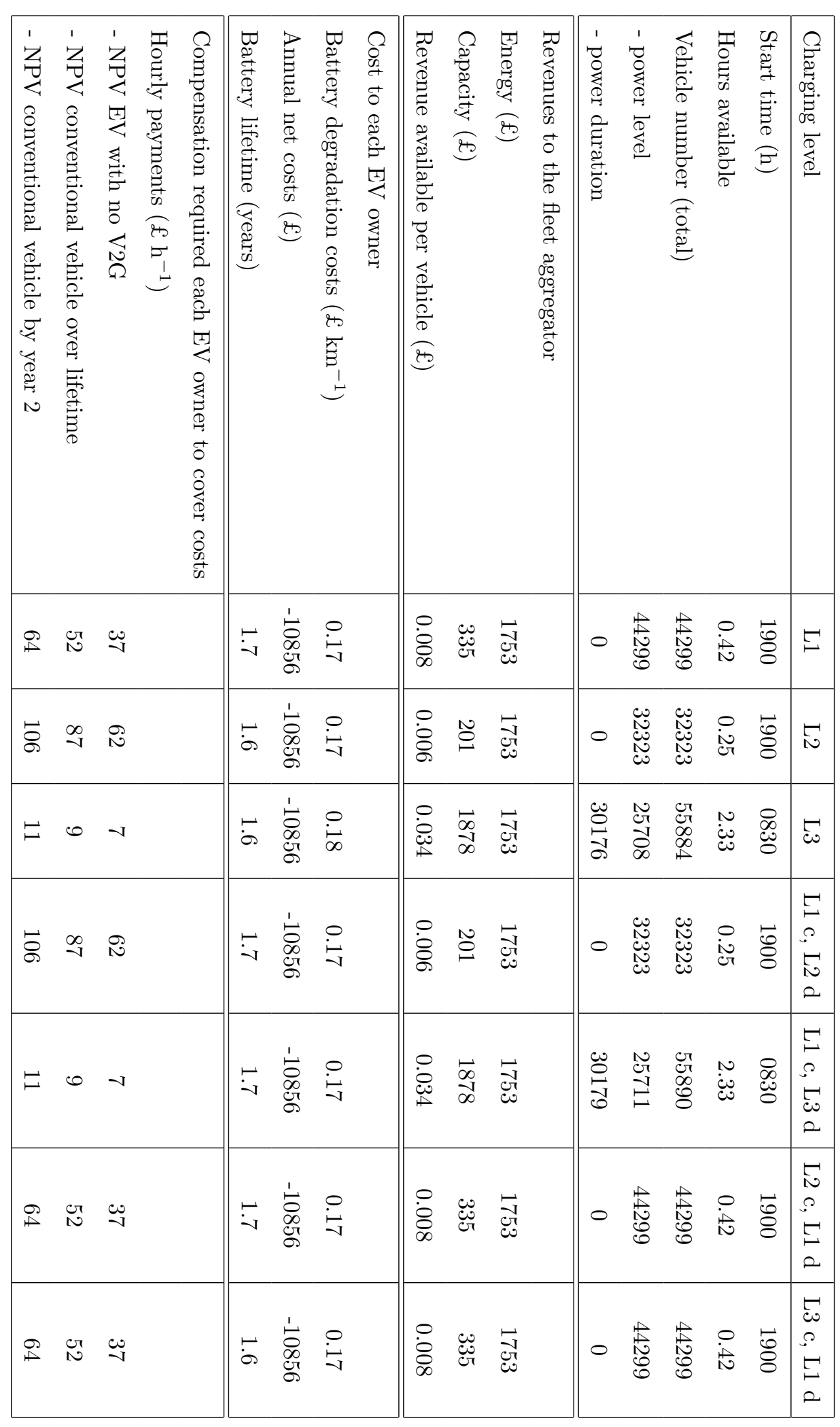


Table A.8: Revenues and costs associated with operating an EV fleet which is providing firm fast reserve by charging opportunistically and across a $20-70 \%$ range of end of life capacity fade criteria.

\begin{tabular}{|c|c|c|c|c|c|c|}
\hline End of life capacity fade criterion (\%) & 20 & 30 & 40 & 50 & 60 & 70 \\
\hline Start time $(\mathrm{h})$ & 1900 & 1900 & 1900 & 1900 & 0830 & 0830 \\
\hline Hours available & 0.42 & 0.58 & 0.42 & 0.33 & 2.67 & 2.33 \\
\hline Vehicle number (total) & 44299 & 62951 & 54302 & 54302 & 118041 & 148963 \\
\hline - power level & 44299 & 44299 & 54302 & 54302 & 54302 & 68527 \\
\hline - power duration & 0 & 18652 & 0 & 0 & 63739 & 80436 \\
\hline \multicolumn{7}{|l|}{ Revenues to the fleet aggregator } \\
\hline Energy $(£)$ & 1753 & 1753 & 1753 & 1753 & 1753 & 1753 \\
\hline Capacity $(£)$ & 335 & 470 & 335 & 268 & 2147 & 1878 \\
\hline Revenue available per vehicle $(£)$ & 0.008 & 0.007 & 0.006 & 0.005 & 0.018 & 0.013 \\
\hline \multicolumn{7}{|l|}{ Cost to each EV owner } \\
\hline Battery degradation costs $\left(£ \mathrm{~km}^{-1}\right)$ & 0.17 & 0.17 & 0.16 & 0.16 & 0.15 & 0.14 \\
\hline Annual net costs $(£)$ & -10856 & -6456 & -6410 & -5557 & -5542 & -5526 \\
\hline Battery lifetime (years) & 1.7 & 2.6 & 3.6 & 4.7 & 5.9 & 7.2 \\
\hline \multirow{2}{*}{\multicolumn{7}{|c|}{$\begin{array}{l}\text { Compensation required each EV owner to cover costs } \\
\text { Hourly payments }\left(£ \mathrm{~h}^{-1}\right)\end{array}$}} \\
\hline & & & & & & \\
\hline - NPV EV with no V2G & 37 & 6 & 8 & 3 & 0.35 & 0.38 \\
\hline - NPV conventional vehicle over lifetime & 52 & 16 & 23 & 21 & 3 & 3 \\
\hline - NPV conventional vehicle by year 2 & 64 & 29 & 40 & 51 & 6 & 7 \\
\hline
\end{tabular}

